\title{
Correction to: Recommendations for the Development and Validation of Neutralizing Antibody Assays in Support of Biosimilar Assessment
}

\author{
D. Gouty, ${ }^{1,17}$ C. C. Cai, ${ }^{2}$ X. Y. Cai, ${ }^{3}$ A. Kasinath ${ }^{4}$ V. Kumar, ${ }^{5}$ S. Alvandkouhi, ${ }^{6}{ }^{\text {J. }}$ Yang, ${ }^{7}$ S. Pederson, ${ }^{8}$ \\ B. Babbitt, ${ }^{9}$ D. Peritt, ${ }^{10}$ A. Rudy, ${ }^{11}$ V. Koppenburg, ${ }^{12}$ A. Dasilva, ${ }^{13}$ M. Ullmann, ${ }^{14}$ S. Liu, ${ }^{15}$ and C. Satterwhite ${ }^{16}$
}

Published online 27 February 2018

\section{Correction to: AAPS J}

https://doi.org/10.1208/s12248-017-0181-6

In the published article, the author B. Babbitt was cited as affiliation 2, but should have been cited as affiliation 9. In addition, there are 2 errors in the affiliations. The correct affiliations are shown in this erratum.

The online version of the original article can be found at https://doi.org/ 10.1208/s12248-017-0181-6

\footnotetext{
${ }^{1}$ BioAgilytix Labs, Durham, North Carolina, USA.

${ }^{2}$ Pfizer Inc, Groton, Connecticut, USA.

${ }^{3}$ WuXi AppTec Co. Ltd, Shanghai, China.

${ }^{4}$ Syngene International Ltd, Bangalore, India.

${ }^{5}$ Biologics, Dr. Reddy's Laboratories Ltd., Hyderabad, India.

${ }^{6}$ BioAgilytix Labs, Durham, North Carolina, USA.

${ }^{7}$ Genentech, Inc, South San Francisco, California, USA.

${ }^{8}$ Alder Biopharmaceuticals Inc., Bothell, Washington, USA.

${ }^{9}$ PAREXEL International Corp, Waltham, Massachusetts, USA.

${ }^{10}$ Pfizer Inc, Cambridge, Massachusetts, USA.

${ }^{11}$ Sandoz Biopharmaceuticals/Hexal AG, Holzkirchen, Germany.

${ }^{12}$ Sandoz Biopharmaceuticals/Hexal AG, Holzkirchen, Germany.

${ }^{13}$ Sandoz Biopharmaceuticals/Hexal AG, Holzkirchen, Germany.

${ }^{14}$ Merck KGA, Geneva, Switzerland.

${ }^{15}$ Apobiologix, Toronto, Ontario, Canada.

${ }^{16}$ Charles River Laboratory, Reno, Nevada, USA.

To whom correspondence should be addressed. (e-mail: dominique.gouty@bioagilytix.com)
} 